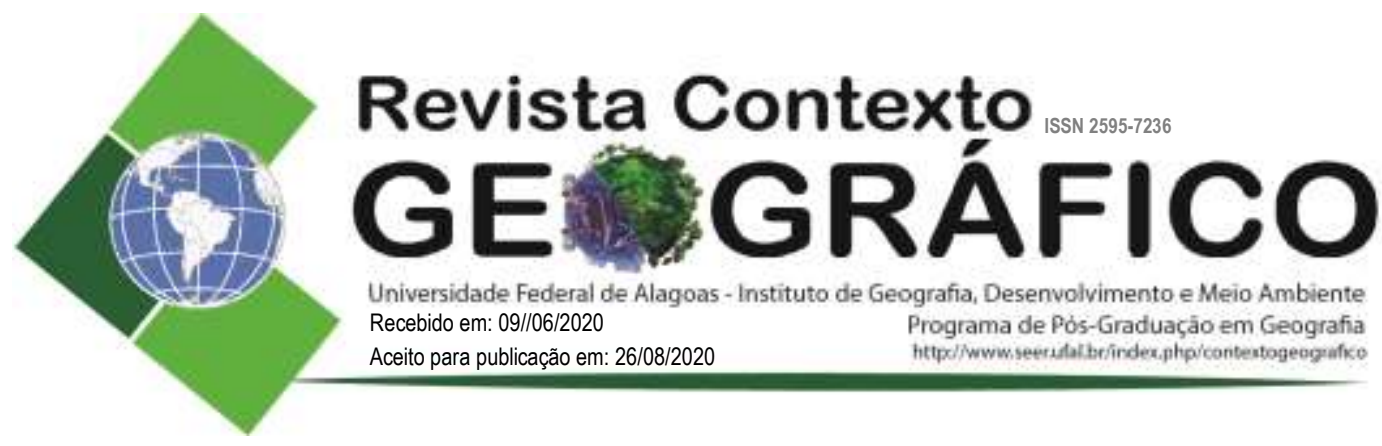

\title{
O LUGAR E O NÃO-LUGAR A PARTIR DA ANÁLISE DA PERCEPÇÃO: UM ESTUDO DE CASO DOS CONSUMIDORES NO SHOPPING CENTER DA CIDADE DE IMPERATRIZ-MA
}

\author{
José Geraldo Pimentel Neto \\ Professor Titular da Faculdade de Imperatriz (FACIMP), Maranhão, Brasil \\ gerageo@gmail.com
}

Isadora Veloso Lima

Coordenadora do Curso de Artes da Faculdade de Imperatriz (FACIMP), Maranhão, Brasil Isadora.lima@facimp.edu.br

Keilha Correia da Silveira

Professora da Universidade Estadual da Região Tocantina do Maranhão (UEMASUL), Imperatriz, Maranhão, Brasil

silveira.kc@gmail.com

\begin{abstract}
RESUMO - O presente artigo tem por objetivo debater o conceito de lugar e não lugar na atual fase do capitalismo globalizado que tem por prática a lógica do consumo e que, em princípio, reorganiza as práticas espaciais simbólicas. A metodologia utilizada, em partes, pelo trabalho de dissertação da pesquisadora Francieli Montanari Gasparin do ano de 2011 que analisou a percepção dos consumidores em um Shopping Center. A partir desse referencial teórico foi construído uma metodologia similar para compreender esse uso em um não lugar geográfico que é o shopping center Imperial da cidade de Imperatriz localizada no Maranhão. Foi utilizado questionário qualitativo com perguntas técnicas da fenomenologia para compreender a percepção dos consumidores e suas condições socioeconômicas. O resultado do debate prático é associado ao referencial teórico sobre os conceitos da geografia humanista de lugar e não-lugar e como se faz a interpretação desses conceitos a partir da lógica da percepção em uma ambiente construído artificializado notadamente definido como não-lugar, pois está associado a realidade do consumo, da globalização e do capital. Esse cenário consumista foi majoritário na pesquisa, mas foi identificada práticas simbólicas nesta pesquisa para este ambiente artificializado notoriamente relacionado ao não-lugar.
\end{abstract}

Palavras-chave: Percepção; Não lugar; Consumidores; Shopping Center; Imperatriz-MA

\section{THE PLACE AND THE NON-PLACE FROM THE ANALYSIS OF PERCEPTION: A CASE STUDY OF CONSUMERS IN THE SHOPPING CENTER OF THE CITY OF IMPERATRIZ-MA}

\begin{abstract}
- his article aims to discuss the concept of place and not place in the current phase of globalized capitalism, which practices the logic of consumption and which, in principle, reorganizes symbolic spatial practices. The methodology used, in part, by the dissertation work by the researcher Francieli Montanari Gasparin in 2011, which analyzed the perception of consumers in a Shopping Center. Based on this theoretical framework, a similar methodology was constructed to understand this use in a non-geographic location, which is the Imperial shopping center in the city of Imperatriz located in Maranhão. A qualitative questionnaire with technical questions from phenomenology was used to understand the perception of consumers and their socioeconomic conditions. The result of the practical debate is associated with the theoretical framework on the concepts of humanist geography of place
\end{abstract}


PIMENTEL NETO, J. G.; LIMA, I. V.; SILVEIRA K. C.
O LUGAR E O NÃO-LUGAR A PARTIR DA ANÁLISE DA PERCEPÇÃO: UM ESTUDO

DE CASO DOS CONSUMIDORES NO SHOPPING CENTER DA CIDADE DE

and non-place and how these concepts are interpreted from the logic of perception in an artificially constructed environment notably defined as non-place, as it is associated with the reality of consumption, globalization and capital. This consumerist scenario was the majority in the research, but symbolic practices were identified in this research for this artificial environment notoriously related to the non-place.

Keywords: Perception; Not place; Consumers; Shopping Center; Imperatriz-MA.

\section{INTRODUÇÃO}

O não lugar é a negação do lugar na teoria da geográfica humanista, ou seja, é o local que possui características artificializadas e que por este motivo não proporciona, em uma perspectiva geral, nenhum tipo de simbolismo perceptivo histórico. Por isso é importante entender as duas visões conceituais supracitadas para ter o melhor entendimento da pesquisa.

De forma sucinta o objetivo desse estudo é mostrar o funcionamento das relações interpessoais em determinados ambientes artificiais, ou seja, que seguem a lógica conceitual do não-lugar, como grande exemplo o shopping center, pois segue a lógica do consumo em uma perceptiva funcional (loja, roupa, comida, entretenimento, eletrônicos, entre outros.), atraindo consumidores para a promoção do processo da prática do consumo que, normalmente, não estão associados a alguma dinâmica da cultura da sociedade local.

Esse processo se caracteriza pelas representações globais do capital tendo com grande característica uma estrutura similar que quando se está nesse ambiente (por exemplo o shopping center), normalmente, não se sabe em que território se está, ou seja, as representações são tão artificializadas, voltadas para o consumo e parecidas que não há como diferenciar pelas estruturas construtivas ou mesmo de dinâmica socioeconômica. Neste sentido, os shopping centers seguem um padrão arquitetônico de construção, uso e tipificação de serviços e lojas como é verificado na pesquisa de Gasparin (2011).

Portanto, esse estudo na cidade de Imperatriz, no seu principal Shopping Center (Imperial Shopping), tende a mostrar como funciona a lógica de consumo dos consumidores imperatrizenses e outros cidadãos de outros municípios (da região). Indicando ainda com o uso dessa estrutura segue na lógica funcional da economia globalizada, ou seja, segue a lógica do capital global.

Um ponto interessante é que para uma parcela das pessoas entrevistadas foi identificado certos traços/laços emocionais e simbólicos na percepção dos entrevistados, indicando uma realidade menos consumista e mais pró-relação social com as pessoas e o local (há algum tipo de relação de sentimento - topofilia - como indica Tuan (2012).

\section{LUGAR E NÃO-LUGAR: A COEXISTÊNCIA NO TERRITÓRIO PARA O ENTENDIMENTO PRÁTICO}

A ciência geográfica, ao longo de sua trajetória histórica, vem desenvolvendo o estudo na categoria espaço, e nesta evolução, têm buscado entender a importância desta categoria para as análises e reflexões de fenômenos sociais, culturais, naturais entre outros. Em uma dessas Essas reflexões, o lugar - conceito voltado as simbologias de uma dada localidade, necessita de avanços, focando a compreensão do processo de construção do mesmo em diversos ambiente da segunda natureza (PIMENTEL NETO, 2006).

Pimentel Neto (2006) indica que historicamente a relação simbólica com um dado local (área geográfica) tem referências nas primeiras civilizações do ocidente, como a Grécia Antiga e Roma. Obviamente, que o termo não era o mesmo, mas sim as perspectivas analíticas do espaço geográfico (espaço produzido pelo homem).

Atualmente, numa perspectiva mais rotineira do cotidiano o termo lugar possui uma conotação de 
PIMENTEL NETO, J. G.; LIMA, I. V.; SILVEIRA K. C..
O LUGAR E O NÃO-LUGAR A PARTIR DA ANÁLISE DA PERCEPÇÃO: UM ESTUDO

DE CASO DOS CONSUMIDORES NO SHOPPING CENTER DA CIDADE DE

IMPERATRIZ-MA

um senso comum de localização de alguma coisa (casa, prédio, ponte, gerando alguma referência geográfica), Mas, na geografia, principalmente na lógica humanista, o referido termo tem uma lógica teórica como demostra a pesquisadora Dirce Maria Antunes Suertegaray, ela indica:

\begin{abstract}
O lugar é um outro conceito, de nosso ponto de vista, operacional em Geografia. Consistiria, a partir da Cartografia, a expressão do espaço geográfico na escala local; a dimensão pontual. Por muito tempo, a Geografia tratou o lugar nesta perspectiva e considerou-o como único e autoexplicável. (Suertegaray, 2001, p. 4)
\end{abstract}

Neste sentido, o conceito de lugar, na geografia, tem uma perspectiva relacional-sentimental, proporcionando uma experiência ${ }^{1}$ de um indivíduo e/ou mesmo um grupo social em uma determinada área geográfica. Em termos histórico-científico o conceito está associado a uma corrente historicista-humanista com características metodológica da fenomenologia e do existencialismo, tratando a partir da lógica do comportamento e da percepção subjetiva de um dado espaço (percepção ambiental).

Essa forma de pesquisa tem como foco o sujeito, pois ele é enquanto o foco da interpretação das coisas ao seu redor, ou seja, aos ambientes de vivência, aos sujeitos com os quais interage e os objetos. Essa linha teórica trabalhar com a interpretação e análise da percepção, gerando compreensões dos processos socioespaciais de uma determinada área. Tuan ${ }^{2}$ (1983), uma das referências sobre o conceito, desenvolve o termo "topofilia" que é a análise de um dado local a partir de laços (positivos ou negativos) de um indivíduo ou grupo social. Ele afirmar essas relações são determinantes do valor simbólico atribuído a um espaço (o lugar) e assim ter visões de mundos peculiares que se "constroem" ao passar do tempo e gerações a partir dos grupos socioculturais que vivem em determinados ambientes ou "habitats" humanos específicos.

Esse termo tem um valor simbólico que soma as ações e as intenções da sociedade na formação do espaço. Junto a isso agrega a dialética crítica na análise da geografia humanista, pois parte da observação das relações de troca (mercado) e de uso (vida da sociedade) e essas relações serão definidas por Tuan (1992) com os não-lugares - ambientes voltados para a lógica do consumo e do capital, mas será que esses ambientes possuem sua simbologia para os indivíduos?

Esse questionamento é, em partes, respondido neste artigo, pois há indícios que mostram nos ambientes artificiais do mercado é possível verificar ambientes simbólicos de espaço vivido e isso estará associado ao processo de formação e consciência nesses locais, ou seja, quanto mais tempo um local artificializado existir mais possibilidades de possuir símbolos para determinadas parcelas da sociedade em um determinado espaço geográfico.

Portanto, a consciência do passado é um elemento importante para a identificação do indivíduo com o lugar, encarada como herança, um legado a ser preservado, algo que enraíza os sentimentos, uma memória que pode ser tanto individual quanto social e que reaparece nas relações pessoais com a simbologia do espaço vivido. Este lócus no qual se articulam o processo identificação e a história social do lugar de forma dinâmica e transformadora do espaço vivido, como afirma Santos (2002) ao dizer que:

No lugar, nosso próximo, se superpõe dialeticamente ao eixo das sucessões, que transmite os tempos externos das escalas superiores e o eixo dos tempos internos, que é o eixo das coexistências, onde tudo se funde, enlaçando definitivamente, as noções e as realidades de espaço e tempo. (Santos, 2002, p. 22)

Desta forma os lugares, quando visto como experiência e vivência, normalmente são dotados de limites 
PIMENTEL NETO, J. G.; LIMA, I. V.; SILVEIRA K. C.
O LUGAR E O NÃO-LUGAR A PARTIR DA ANÁLISE DA PERCEPÇÃO: UM ESTUDO

DE CASO DOS CONSUMIDORES NO SHOPPING CENTER DA CIDADE DE

IMPERATRIZ-MA

reconhecíveis pelo mapa mental desenvolvido pelo ser e/ou grupo social. As mudanças geradas pelo processo de produção do espaço capitalista podem mudar essa dinâmica de percepção simbólica, gerando a diminuição das práticas do cotidiano e aumentando as práticas mercadológicas do capital vinculado ao modo de produção capitalista.

Leite (1998) apresenta outra acepção de lugar, compreendido enquanto expressão geográfica de singularidade, descentrada, universalista e objetiva. Trata-se na realidade de uma visão na qual o lugar é considerado tanto como produto de uma dinâmica que é única, ou seja, resultante de características históricas e culturais intrínsecas ao seu processo de formação, quanto como uma expressão da globalidade, em resumo, é um ambiente híbrido multifacetado com as coexistências dos espaços opacos e luminosos como é verificado em Santos (2002).

Da mesma forma Harvey (1995 p. 221) interpreta essa relação indicando que esses espaços possuem "a acumulação de riqueza, de poder e de capital passou a ter um vínculo como conhecimento personalizado do espaço e o domínio individual dele”. Essa acumulação de riqueza, de poder e de capital passou a ter um vínculo com o conhecimento personalizado do espaço e o domínio individual cuja enfatiza as diferenciações dos lugares, sendo dinâmicos ou estagnados, Harvey (2004).

Não que os lugares tenham perdido seus valores psicológicos e existencialistas, mas a principal forma de hierarquizar lugares em nossa sociedade, visto por Harvey (1995), é a partir de suas funções (sociais, econômicas, culturais e políticas). Assim, o lugar de trabalho se distanciou do lugar de lazer, de morar, de prestar devoção ou do "lugar".

O lugar, não estando mais vinculado diretamente àquelas características originais, torna-se manipulável pelos agentes que transformam tudo em consumo, tudo em mercadoria - transformam em um não lugar ou, pelo menos, em ambientes híbridos coexistentes em que o sistema global tenderá a possuir mais força de atuação nesse espaço.

Junto a essa afirmação Debord (2003) enfatiza que os lugares, por influência do capital econômico, tendem a valorizar as funções e as relações capitalistas ${ }^{3}$ perdendo assim as relações mais humanistas. Ele enfatiza em seu livro sociedade do espetáculo que os lugares ${ }^{4}$ não possuem uma única identidade por isso existem diversos conflitos:

\begin{abstract}
Subproduto da circulação das mercadorias, a circulação humana considerada como consumo, o turismo, reduz-se fundamentalmente à distração de ir ver o que já se tornou banal. A ordenação econômica dos frequentadores de lugares diferentes é por si só a garantia da sua pasteurização ${ }^{5}$. A mesma modernização que retirou da viagem o tempo, retirou-lhe também a realidade do espaço (Debord, 2003, p. 69).
\end{abstract}

Dessa forma, um grupo de pessoas, as elites, podem modificar a histórica, suas características físicohumanas, de uma determinada localidade. Em âmbito local, cada lugar, reage de uma maneira própria, a partir de condições pré-existentes, ou seja, a partir de um conjunto de fatores - cultura, tradição, língua, hábitos, fatores externos, econômicos e políticos.

Nessa perspectiva o lugar constitui a dimensão da existência e coexistência ${ }^{6}$ que se manifesta através "de um cotidiano compartilhado entre as mais diversas pessoas, firmas, instituições - cooperação e conflito são à base da vida em comum" (Santos 2002). O lugar está às representações da vida cotidiana, o valor, a representação pessoal, a coisa, os lugares que unem e separam pessoas a partir dos seus fatores simbólicos.

Assim cada lugar ${ }^{7}$, para Santos (2000), é o encontro das verticalidades ${ }^{8}$ - o ponto no espaço separado na qual garante o funcionamento global da sociedade e da economia e as horizontalidades ${ }^{9}$ - é o ponto de homogeneidade entre a sociedade e a economia fixados no espaço e agregados continuamente no mundo globalizado. Ou seja, a verticalidade é a representação dos fenômenos em escala global e a horizontalidade é a representação dos fenômenos em escala territorial local - podendo ser a cidade.

Neste sentido, aponta Santos (2005), que existe uma relação de coexistência entre as horizontalidades e 
PIMENTEL NETO, J. G.; LIMA, I. V.; SILVEIRA K. C..
O LUGAR E O NÃO-LUGAR A PARTIR DA ANÁLISE DA PERCEPÇÃO: UM ESTUDO

DE CASO DOS CONSUMIDORES NO SHOPPING CENTER DA CIDADE DE

as verticalidades na qual se trata de duas escalas de abordagem diferenciadas. A primeira se apresenta como áreas formadas de pontos que se agregam sem descontinuamente e a segunda, representa como pontos no espaço que se separam (descontinuidade) e determina o funcionamento da economia na rede global. Essa relação de coexistência também é para a lógica do lugar e não-lugar nos diversos territórios.

Por isso, o lugar, segundo Nogueira (2004), é um processo de eventos históricos que se caracterizam por práticas institucionais e individuais articuladas, que se unem às características estruturais da sociedade. Embora os componentes do lugar sejam específicos na medida em que ocorrem as interações com as escalas regionais, estaduais, nacionais, supranacionais e mundiais o processo de formação e transformação, as leis gerais tendem a modificar de acordo com as características as especificidades e necessidades do capital (globalização) em dada localidade.

A evolução desses processos faz do lugar uma parte da superfície terrestre que é singular, porém essa situação vinculada às redes físicas (Ferrovia, Rodovia, Telegrafia, Telefonia e Teleinformática). E a contração espaço-tempo ${ }^{10}$ (a partir das inovações tecnológicas globalizadas) faz com que os locais se inseriram em múltiplas escalas, desde a regional a mundial, assim confirmando a relação entre o todo e a parte como aponta Santos (2002). E é esse todo com a parte que proporciona o surgimento de nãolugares no lugar. Ou seja, as necessidades, de acordo com o tamanho e funcionalidade do lugar em relação ao sistema econômico globalizante.

Essa lógica é a fonte da especificidade do lugar deve ser encontrada no capitalismo que hoje é caracterizado pelas relações globais, promovendo a diferenciação geográfica das relações sociais, induz e gera o desenvolvimento das determinadas áreas geográficas e assim tornando-as, promotoras de lugares específicos, singulares que alguns se inserem na globalização (espaços luminosos) e outro ficam de fora da globalização (espaços opacos). Novamente podemos verificar a lógica do não-lugar como sendo um espaço luminoso dentro de vários outros no lugar que para esse estudo é a cidade de Imperatriz no Maranhão.

Portanto, depois de observado em Tuan (1983 e 2012); Harvey (1995 e 2004); Debord (2003); e Santos (2000 e 2002) o conceito de lugar é analisado na seguinte questão: um espaço de "identidades" com formações históricas e relações de poder, de desconstrução e reconstrução, contínuas que vão se materializando a partir de uma perspectiva multifacetada durante o tempo com seus diversos eventos no processo capitalista contemporâneo. E esse processo supracitado gera a lógica do não-lugar, pois eles coexistem no mesmo ambiente e nos mesmos eventos.

É importante compreender que os eventos não se dão isoladamente, mas em conjunto sistêmico (SANTOS, 2002: 179) e que o lugar decorre destes eventos históricos caracterizados por práticas institucionais e individuais articuladas em um ambiente, que se unem às características estruturais dada sociedade em um local.

Embora os componentes do Lugar sejam universais na medida em que ocorrem as interações com outras escalas geográficas, o processo de formação e transformação tende a modificar-se as escalas geográficas (local, regional, nacional etc.). Esse é um ponto interessante da pesquisa, pois a indícios que os não-lugares, mesmo com eventos e histórias distintas, geram percepção de uso do espaço simbólico, ou seja, de um uso voltado para as práticas do particular, do simbólico do indivíduo.

Por este motivo é importante compreender a lógica dos eventos nos não lugares dentro de um lugar, pois é essa dinâmica entre o global e o local se constrói as perspectivas de compreensão do espaço urbano globalizado voltado ao consumo e para as práticas sociais simbólicas. Por isso, é viável essa análise comportamental dos consumidores no shopping center em Imperatriz no Maranhão, pois, gerou interpretações de como a população compreende essa dinâmica globalizante no local. Os próximos passos estão associados à metodologia e aos resultados dessa pesquisa. 
PIMENTEL NETO, J. G.; LIMA, I. V.; SILVEIRA K. C..
O LUGAR E O NÃO-LUGAR A PARTIR DA ANÁLISE DA PERCEPÇÃO: UM ESTUDO

DE CASO DOS CONSUMIDORES NO SHOPPING CENTER DA CIDADE DE

\section{METODOLOGIA}

O procedimento técnico-metodológico da referida pesquisa desenvolveu-se a partir de um levantamento bibliográfico que se remete ao tema, pautando-se em obras de consagrados doutrinadores em conjunto com artigos científicos e demais publicações congruentes.

Quanto ao planejamento de caráter bibliográfico, conforme (GIL, 2008), que define que a pesquisa bibliográfica se desenvolve por meio de materiais já elaborados, constituindo principalmente de livros e artigos científicos que se relaciona com o tema. O método científico para o desenvolvimento desta pesquisa é fenomenológico, voltado para uma análise da percepção da sociedade de um determinado território que tem como base científica o pesquisador Tuan $(1995,2012)$.

A partir da base conceitual foram desenvolvidos os procedimentos metodológicos que tiveram como base o trabalho da pesquisadora Gasparin (2011) que desenvolveu um trabalho de análise da percepção do consumidor em um shopping center, sendo assim, a base norteadora da metodologia desta pesquisa. Por se tratar de uma pesquisa metodológica/fenomenológica o foco é o sujeito e suas observações/percepções sobre o respectivo fenômeno no ambiente construído.

Para tal ação ter sentido científico foi necessário o desenvolvimento e aplicação de questionário no local da pesquisa. O questionário tinha seis perguntas relacionadas com a percepção do consumidor no Imperial Shopping em Imperatriz-MA e cinco pergunta mais sobre o seu perfil socioeconômico. As entrevistas foram desenvolvidas por alunos de um curso de férias proporcionado pelo Núcleo de Artes da Faculdade de Imperatriz - Facimp, objetivando a capacitação dos seus respectivos alunos e pessoas que quisessem fazer o curso.

Se prontificaram cinco alunos do curso de férias para desenvolver a atividade técnica de aplicação do questionário. O professor do curso participou da ação mostrando as formas de abordagem, registrando as imagens e decodificando algumas informações de alguns entrevistados. Essa ação pode ser verificada na Figura 1 que foi escolhida como imagem representativa do processo metodológico de aplicação da entrevista.

Figura 1. Desenvolvimento da pesquisa no Imperial Shopping - Imperatriz-MA

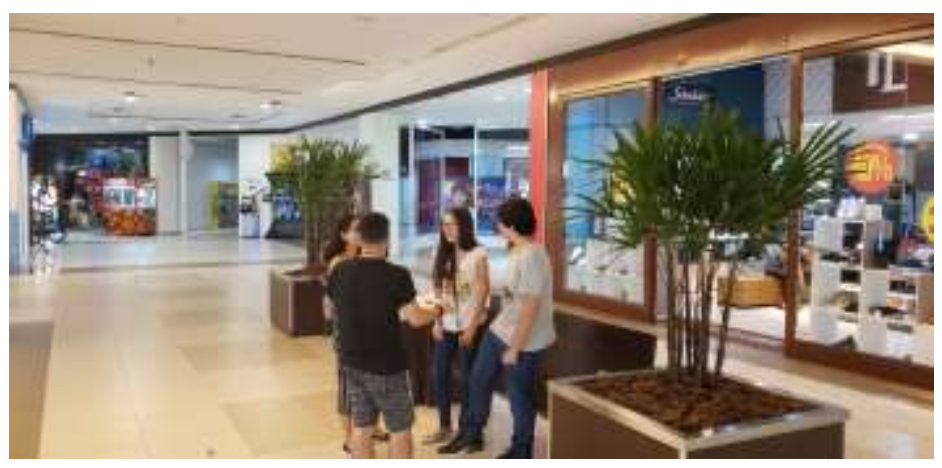

Fonte: Geraldo Pimentel (2020)

Essa pesquisa teve como base um curso de férias que debatia a teoria da relação da percepção com os diversos ambientes, tendo como bases os conceitos de Tuan $(1995,2012)$ sobre lugar, não-lugar e topofilia. Essas teorias foram associadas a metodologia para gerar a interpretação do ambiente construído (Imperial Shopping) e como cada pessoa, ou seja, o sujeito da pesquisa, interpreta, percebe e transita nesse espaço. A data da pesquisa foi dia 22/01/2020 período de férias no município que proporciona uma situação inversamente distinta para as grandes capitais que nesse período os shoppings ficam lotados.

Nesse caso, a maioria da população estava viajando e só voltam depois do mês de janeiro. 
PIMENTEL NETO, J. G.; LIMA, I. V.; SILVEIRA K. C..
O LUGAR E O NÃO-LUGAR A PARTIR DA ANÁLISE DA PERCEPÇÃO: UM ESTUDO DE CASO DOS CONSUMIDORES NO SHOPPING CENTER DA CIDADE DE

Normalmente esse tipo de situação está associado a lógica das cidades médias que tem muita saída, no período de férias, de uma parcela da população que volta para suas cidades de origem. Visto que Imperatriz é uma cidade polo na área de educação superior (rede privada e pública), industrial com a indústria Suzano, o agronegócio e um sistema de saúde (público e privado) que atende uma região a cidade comporta essa lógica de cidade média com grande gravitação para esses serviços, mas no período de férias uma parcela da população volta para suas cidades de origem.

A base metodológica para o desenvolvimento das perguntas sobre a percepção do consumidor é de Gasparin (2011). Foram feitas um total de 46 perguntas, ou seja, foram analisadas 46 pessoas, dentro de um tempo estabelecido que foi das $14 \mathrm{~h}$ até às $18 \mathrm{~h}$. As primeiras seis perguntas estão a base da pesquisa, focando a parte da análise da percepção dos consumidores no não-lugar, são elas:

1. Quando eu digo Shopping Center Imperial, qual a primeira coisa que lhe vem à mente?

2. Que outras ideias the vêm à mente quando você escuta Imperial Shopping?

3. Como você descreve o Shopping Center Imperial?

4. Quais sentimentos lhe vêm à mente quando eu digo Imperial Shopping?

5. Quais os benefícios que o Imperial Shopping oferece para você?

6. Qual o significado do Imperial Shopping para você?

Após essas perguntas foi desenvolvido um grupo de perguntas voltada para a análise sócio economia de cada entrevistado, objetivando ver em qual estrato social de cada entrevistador, como também, as questões de gênero, faixa etária, escolaridade e frequência no shopping, seguem as perguntas:

Gênero (sexo):

a. ( ) Masculino b. ( ) Feminino.

Faixa Etária (anos):

a. ( ) 18-25, b. ( ) 26-35, c. ( ) 36- 45, d. ( ) 46-65, e. ( ) mais de 65 .

Grau de Escolaridade:

a. ( ) Ensino fundamental incompleto, b. ( ) Ensino fundamental completo, c. ( ) Ensino médio incompleto, d. ( ) Ensino médio completo, e. ( ) Ensino superior incompleto, f. ( ) Ensino superior completo, g. ( ) Pós-graduação incompleto, h. ( ) Pós-graduação completo.

Renda individual mensal:

a. ( ) até $\mathrm{R} \$ 600,00$; b. ( ) de $\mathrm{R} \$ 601,00$ a $\mathrm{R} \$ 1.200,00$; c. ( ) de $\mathrm{R} \$ 1.201,00$ a $\mathrm{R} \$ 2.000,00$; d. ( ) de $\mathrm{R} \$ 2.001,00$ a $\mathrm{R} \$ 3.400,00$; e. ( ) de $\mathrm{R} \$ 3.401,00$ a $\mathrm{R} \$ 6.500,00$; f. ( ) mais de $\mathrm{R} \$$ $6.501,00$.

Frequência mensal em que vai ao Shopping Center Imperial, em média:

a. ( ) menos de 1 vez, b. ( ) de 1 a 3 vezes, c. ( ) 4 ou mais vezes.

Para os questionamentos da percepção se chegou a um resultado de 143 tipos de percepção. Esse total é diferente do de quantidade de pessoas porque cada entrevistado poderia colocar quantas percepções ele acharia cabível para o local - Imperial Shopping. No Quadro 1 os tipos de distribuições desenvolvidos no artigo que tem como base a pesquisa de Gasparin (2011). 
Quadro 1: distribuição dos fatores e características

\begin{tabular}{|l|l|}
\hline Fator & \\
\hline Cognitivo & facilidade \\
\hline economia \\
\hline gastos \\
\hline Subtotal \\
\hline Emocica \\
\hline diversão \\
\hline local de encontro com amigos \\
\hline aconchegante \\
\hline momentos felizes \\
\hline engraçado \\
\hline alegria \\
\hline satisfação \\
\hline prazer \\
\hline emoção \\
\hline felicidade \\
\hline paz \\
\hline calma \\
\hline Subtotal \\
\hline lojas \\
\hline compras \\
\hline comida \\
\hline localização \\
\hline variedades \\
\hline roupa \\
\hline praticidade \\
\hline entretenimento \\
\hline eletroeletrônicos \\
\hline cinema \\
\hline trabalho \\
\hline Subtotal \\
\hline passeio \\
\hline distração \\
\hline família \\
\hline beleza \\
\hline diversão \\
\hline algo boom \\
\hline desestresse \\
\hline amigos \\
\hline Subtotal \\
\hline
\end{tabular}

Fonte: Gasparin (2011)

Essa é a estrutura dos procedimentos metodológicos deste artigo. Qualquer nova informação será inserida nos resultados, pois alguns detalhamentos necessitaram de um explicações científicas que com a interpretação dos dados e a relação da teoria proporcionaram uma melhor compreensão da pesquisa e, portanto, justificando um detalhamento dos procedimentos 
PIMENTEL NETO, J. G.; LIMA, I. V.; SILVEIRA K. C..
O LUGAR E O NÃO-LUGAR A PARTIR DA ANÁLISE DA PERCEPÇÃO: UM ESTUDO DE CASO DOS CONSUMIDORES NO SHOPPING CENTER DA CIDADE DE

metodológicos não citados nesta etapa. O próximo tópico é a análise dos resultados sobre a pesquisa da percepção dos consumidores no Imperial shopping da cidade de Imperatriz-MA.

\section{SHOPPING CENTER É LUGAR DE CONSUMO OU DE EXPERIÊNCIAS LOCAIS: UM ESTUDO DE CASO NO IMPERIAL SHOPPING EM IMPERATRIZ NO MARANHÃO}

Em um primeiro momento é importante destacar o que é o município de Imperatriz ${ }^{11}$ do Maranhão para a região. O município está inserido na Mesorregião Oeste Maranhense e possui, de acordo com Censo do IBGE de 2010 uma área de $1.369 \mathrm{~km}^{2}$, tendo uma população de 247.553 habitantes e uma densidade demográfica de 180,8 habitantes $/ \mathrm{km}^{2}$. É um polo de educação superior contendo mais de 5 instituições privadas, um polo industrial com uma planta da Suzano S/A e um polo médico hospitalar.

Além disso, tem um poder gravitacional para toda região na perspectiva de serviço, ponto da pesquisa, pois na localidade há três shoppings dois no centro da cidade, Timbira e Tocantins, e o da pesquisa que se chama Imperial Shopping que fica na Rodovia BR-010, 100 área de expansão da cidade.

De acordo com o sítio Tiendeo (https://www.tiendeo.com.br/imperatriz) a estrutura é a seguinte: "O Imperial Shopping conta com três pavimentos, sendo um subsolo destinado a estacionamentos e dois pisos para estabelecimentos comerciais, nos quais serão distribuídas cerca de 177 lojas. Destaque para dez lojas âncoras e semi-âncoras e cinco salas de cinema tipo "multiplex stadium". Essa estrutura pode ser materializada com a partir da Figura 2 a seguir.

Figura 2. Imperial Shopping

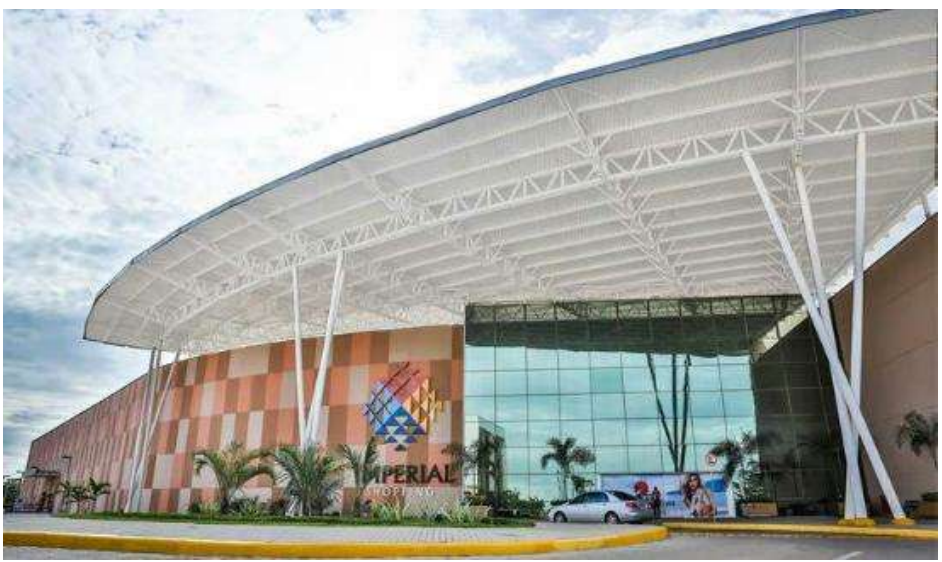

Fonte: Tripadvisor (2020)

É o maior shopping da região, com mais lojas, maior praça de alimentação e de diversão, portanto uma das principais áreas de lazer privada da cidade. Em resumo, o shopping está em uma área de influência de grandes projetos de expansão da região. É nesse cenário que a pesquisa foi desenvolvida para identificar como a população percebe o shopping, pois, mesmo sem entender a teoria e a metodologia, eles, a partir do questionário, respondem suas percepções, ou seja, seus sentimentos e/ou vontades e/ou aspirações quando estão ou vão para à localidade.

Os resultados da pesquisa na lógica socioeconômica foram a seguintes: 1) para a questão do gênero a maioria das pessoas entrevistadas foram do gênero feminino com $65 \%$ do total da amostra que é de 46 entrevistados. Como foi uma pesquisa de um dia e só entrevistamos pessoas que aceitaram responder o questionário é possível que a fator cultural ajude a responder essa 
PIMENTEL NETO, J. G.; LIMA, I. V.; SILVEIRA K. C..
O LUGAR E O NÃO-LUGAR A PARTIR DA ANÁLISE DA PERCEPÇÃO: UM ESTUDO DE CASO DOS CONSUMIDORES NO SHOPPING CENTER DA CIDADE DE

pergunta, pois o gênero masculino, aparentemente, é mais reativo para o desenvolvimento de respostas para o respectivo questionário.

Sobre a faixa etária é verificado que a pesquisa teve como o maior índice a faixa de população de 18 até 25 anos. Faz sentido pelo período da pesquisa que é férias (foi em janeiro) e as escolas e faculdades estão de recesso. Cerca de $43 \%$ da amostra foi dessa faixa. A seguir a Figura 3 com as outras faixas etárias. A segunda faixa mais representativa foi a de 26 até 35 anos, para muitos ainda considerado jovens, portanto, seria o contínuo da explicação supracitada.

Figura 3. Faixa etárias

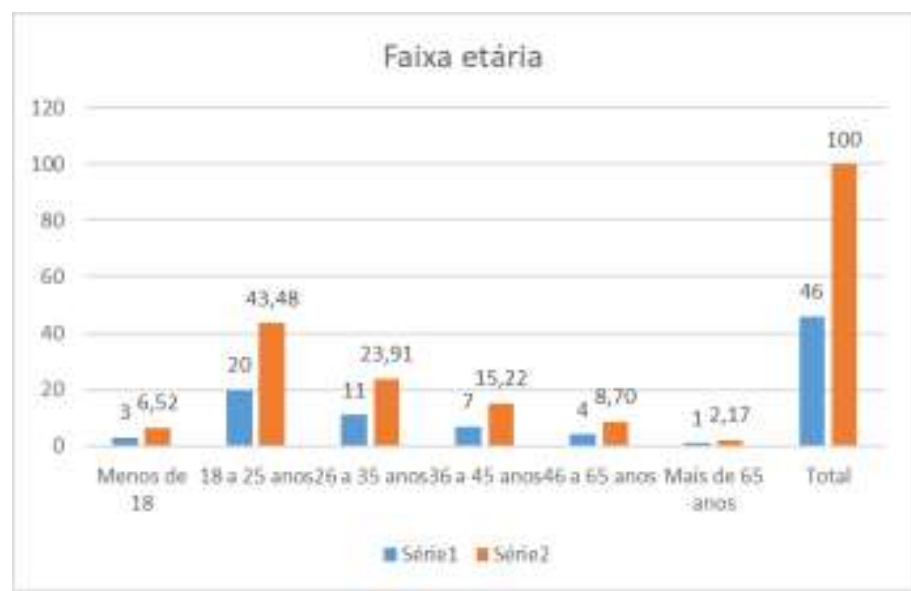

Fonte: Os Autores (2020)

Seguindo com os dados socioeconômicos a escolaridade com maior indicador foi a do ensino médio completo, que ratifica a suposição com a faixa etária em relação ao período da pesquisa no mês de férias escolares e das faculdades indicando que um dos principais pontos de lazer é a estrutura do shopping center. Logo depois a segunda mais representativa foi a de nível superior, indicando a relação com o poder aquisitivo (pessoas podendo estar mais consolidadas financeiramente) e que, na pesquisa, estavam associadas ao segundo estrado da idade de idade (26-35 anos). O restante dos graus de escolaridades segue na Figura 4.

Figura 4. Grau de escolaridade.

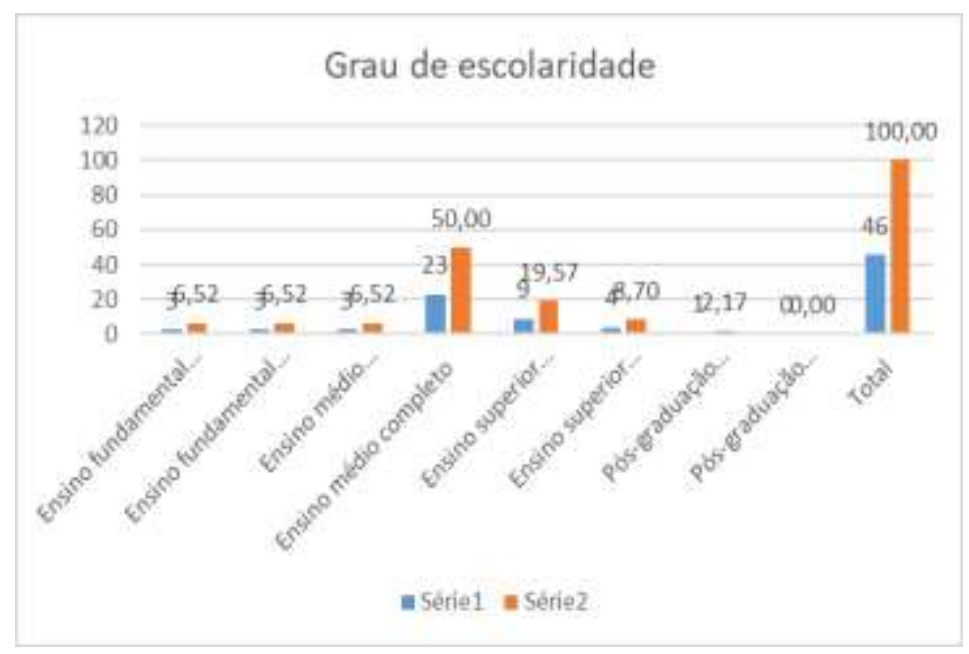

Fonte: Os Autores (2020) 
PIMENTEL NETO, J. G.; LIMA, I. V.; SILVEIRA K. C..
O LUGAR E O NÃO-LUGAR A PARTIR DA ANÁLISE DA PERCEPÇÃO: UM ESTUDO DE CASO DOS CONSUMIDORES NO SHOPPING CENTER DA CIDADE DE

O próximo indicador é a faixa de renda, dado que gerou muita distorção, ora porque alguns não queriam responder (suposição de constrangimento), ora por não saber, pois como mais de $40 \%$ eram pessoas com idade entre 18 até 25 anos, muitos não tinham ideia de sua renda, indicadores de "sem renda" ou não respondendo. Inclusive é um dos pontos que merece uma revisão no procedimento da pergunta do questionário. Os maiores indicadores foram "sem renda" e entre 600 reais até 1.200 reais, ambos tiveram $20 \%$ do total da amostra. A seguir um a Figura 5 com os restantes dos dados, inclusive é o único indicador que não tem 46 no total de entrevistados porque 11 entrevistados não sabiam ou não quiseram responder.

Figura 5. Faixa de renda

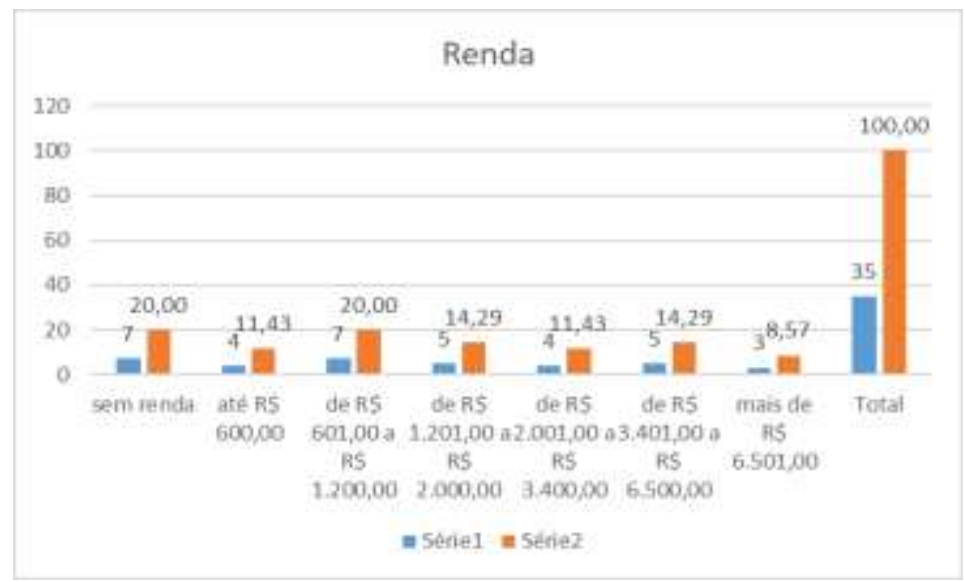

Fonte: Os Autores (2020)

Por fim o último indicador que é voltado para frequência ao uso do equipamento urbano, o shopping. Com as os dados indicam a estrutura é muito usada pela população e isso é verificado no questionário, pois o maior índice é de mais de 4 vezes indo ao respectivo shopping, tendo um percentual de $43 \%$. E logo depois o segundo percentual é de 1 até 3 vezes, em resumo, aproximadamente $85 \%$ da população entrevistada vai, pelo menos, uma vez para o shopping por semana e destaca-se que o estrato analisado é de 1 até 4 ou mais vezes, Na Figura 6 é possível ver as outras frequências de idas ao respectivo shopping center.

Figura 6. Frequência no estabelecimento

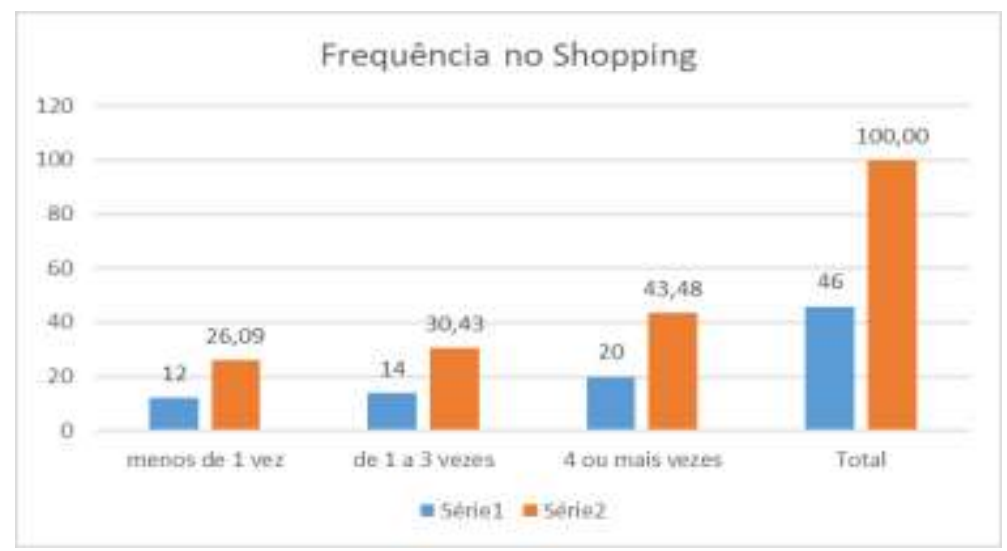

Fonte: Os Autores (2020) 
PIMENTEL NETO, J. G.; LIMA, I. V.; SILVEIRA K. C..

Por fim, a análise mais importante que é a situação da percepção do consumidor no local, ou seja, no Imperial Shopping. É importante destacar que houve um total de 43 respostas porque para este ponto do questionário o entrevistado poderia dar várias respostas, não havia, quantitativo (nem mínimo nem máximo) é sua visão sobre as seis perguntas na lógica da percepção fenomenológica. $\mathrm{O}$ resultado da Figura 7 indica uma relação o que é definido nas teorias sobre o ambiente shopping center, pois $34,27 \%$, totalizando 49 respostas, foi para questão funcional do estabelecimento como mostra o Quadro 1.

Figura 7. Análise da percepção do consumidor no Shopping

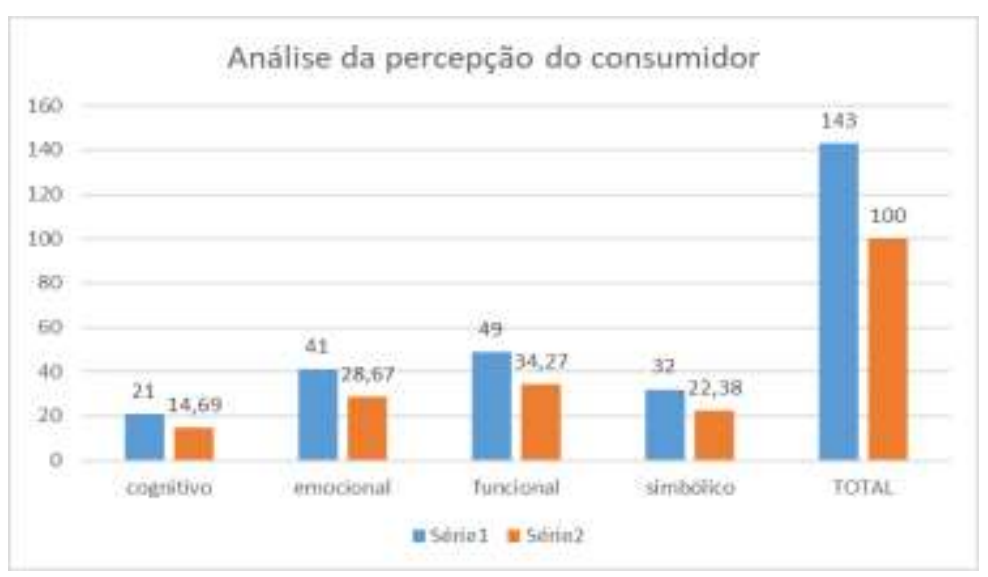

Fonte: Os Autores (2020)

Ou seja, a maioria, mesmo sem saber dos conceitos sobre lugar e não-lugar responderam que a sua ida ao shopping é para o uso funcional. Um dado importante é que o fator emocional também teve um indicador alto, tendo um valor em percentual de 28,67\%. Essa variável indica que o Imperial Shopping tem um viés humanístico para uma parte da amostra e que como ela só foi feita em um dia esse resultado pode ser diferente. Portanto, é importante destacar que uma nova aplicação é necessária com maior tempo de pesquisa e fora do período de férias. Porém, as conclusões preliminares sobre a pesquisa é que o não-lugar é a conceito para as pessoas da amostra no Imperial Shopping.

\section{CONCLUSÃO}

Os estudos fenomenológicos são de suma importância para compreensão do comportamento da sociedade nas micro escalas geográfica como, por exemplo, o shopping center. Segundo Tuan (2012) a topofilia é um dos importantes conceitos para a compreensão da relação de um determinado sujeito com um determinado lugar, é a relação de sentimento, de pertencimento sobre um determinado estabelecimento que está associado ao local e que em algumas situações, por conta do modo de produção capitalista, a lógica do capital e consumo são incorporadas no localidade.

É a partir dessa lógica de pertencimento que um ambiente construído se tem o simbolismo social para uma parcela da sociedade ou, em outros momentos, a "simples" relação de consumo gerada pelo capital e associada a lógica da globalização. Essa é a dualidade entre os conceitos de lugar e não-lugar trabalhos por Tuan (1995).

Está pesquisa teve como objetivo esse debate da fenomenologia que tinha como foco a análise comportamental da população de Imperatriz no Maranhão sobre um ambiente construído muito 
PIMENTEL NETO, J. G.; LIMA, I. V.; SILVEIRA K. C..
O LUGAR E O NÃO-LUGAR A PARTIR DA ANÁLISE DA PERCEPÇÃO: UM ESTUDO DE CASO DOS CONSUMIDORES NO SHOPPING CENTER DA CIDADE DE

popular e usado pela sociedade que é o Imperial Shopping. Local muito frequentado pela população por diversos fatores, desde o clima tropical até os fatores de lazer e consumo, pois há mais de 170 lojas neste local sendo o maior shopping da região.

Os resultados da pesquisa, mesmo tendo uma temporalidade pequena e que pode ter alterado o resultado, indicam que para as 46 pessoas entrevistadas em 22/01/2020 o Imperial Shopping é um local de consumo, tendo um objetivo funcional para mais de $30 \%$ dos entrevistados. Essa realidade correlaciona com a visão teórica que é colocado para o pesquisador Tuan (1995 e 2012) quando indica que os não-lugares possuem uma lógica com o capital globalizado e pouca referência com simbólico ou mesmo o emocional.

Porém, como mencionado, essa pesquisa verificou que houve um indicador quantitativo representativo das respostas para a realidade simbólica (particular), mesmo estando em um ambiente voltado para a lógica de consumo globalizante. Em números o resultado para a perspectiva emocional ficou acima dos $25 \%$, gerando possiblidades de interpretações sobre a perspectiva emocional neste ambiente.

Para se ter mais subsídios sobre essa situação são necessárias mais pesquisas sobre essa temática, tendo mais tempo de pesquisa, que pode ser um problema neste caso (foi feita em janeiro/2020 período de férias), e em outros shoppings centers no Brasil e pelo mundo. Talvez após essas análises poderemos ter uma nova interpretação do que se vem denominando de nãolugar no capitalismo globalizante voltado para o consumo.

\section{AGRADECIMENTOS}

Essa pesquisa fez parte de uma atividade de curso de férias desenvolvido na Faculdade de Imperatriz (Facimp) que proporcionou as atividades técnicas na estrutura do Imperial Shopping em Imperatriz no Maranhão. Além disso, agradecer aos alunos que participaram da pesquisa, são eles: Brenda Larissa Valuar Costa, Raquel Guimarães de Sousa, Nayane Alves Araújo e Leandro Cruz Bezerra. Sem a colaboração deles não haveria como ter tidos os dados da pesquisa. Agradecemos à todos pela ajuda no trabalho de campo.

\section{REFERENCIAS}

CASTELLS, Manuel. A Sociedade em rede. São Paulo: Paz e Terra, 2000.

DEBORD, Guy. A Sociedade do Espetáculo. Rio de Janeiro: Contraponto. 2003

GASPARIN, Francieli Montanari. A configuração da imagem de um shopping center na percepção de consumidores locais. 2011, 115f. (Dissertação de mestrado). Universidade de Caxias do Sul, Programa de Pós-Graduação em Administração - PPGA, 2011.

HARVEY, David. A condição pós-moderna: uma pesquisa sobre as origens da mudança cultural. São Paulo: Loyola, 1989 (3. ed.).

. Espaços de Esperança. São Paulo: Loyola, 2004.

A produção capitalista do espaço. São Paulo: Annablume, 2005

Instituto Brasileiro de Geografia e Estatística (IBGE). Cidades. Rio de Janeiro: IBGE, 2020.

Censo 2010. Rio de Janeiro: IBGE, 2010.

LEITE, Adriana. Lugar: duas acepções geográficas. In: Anuário do Instituto de Geociências. Rio de janeiro: UFRJ, 1998.

MASSEY, Doreen. Um sentido global do lugar. In: ARANTES, Antônio (Org.). O espaço da diferença. Campinas: Papirus, 2000. p. 176-185. 
PIMENTEL NETO, J. G.; LIMA, I. V.; SILVEIRA K. C..
O LUGAR E O NÃO-LUGAR A PARTIR DA ANÁLISE DA PERCEPÇÃO: UM ESTUDO

DE CASO DOS CONSUMIDORES NO SHOPPING CENTER DA CIDADE DE IMPERATRIZ-MA

MILAN, Gabriel Sperandio; GASPARIN, Francieli Montanari; TONI, Deonir De. A configuração da imagem de um shopping center na percepção de consumidores locais. REAd. Rev. eletrôn. adm. (Porto Alegre), Porto Alegre, v. 19, n. 1, p. 83-114, Apr. 2013.

PIMENTEL NETO, José Geraldo. Pólo Médico do Recife e a globalização: a singularidade da localidade e os efeitos da pós-modernidade. v. 23, n. 2 Revista de Geografia (Recife), 2006

SANTOS, Milton. A natureza do espaço - Técnica e tempo. Razão e emoção. São Paulo: Hucitec, 2000. Record, 2000.

Por uma outra globalização: do pensamento único à consciência universal. São Paulo:

SUERTEGARAY, D. M. A. Espaço geográfico uno e múltiplo. Rev. Scripta Nova. Vol. V, Universidad de Barcelona, 2001.

TUAN, Yi-Fu. Espaço e Lugar: a Perspectiva da Experiência. São Paulo, DIFEL, 1983. 250 p

Londrina, 2012.

Topofilia - um estudo da percepção. EDUEL - Editora da Universidade Estadual de

\begin{abstract}
${ }^{1}$ A consideração desse lugar vem das ideias de Heidegger e Sartre apud Duarte \& Matias (2005) quando enfocam o homem como aquele que arruma, desarruma, organiza e significa o homem, deste modo é que podemos afirmar que só situados é que percebemos as particularizações do espaço
\end{abstract}

${ }^{2}$ A definição de lugar para Tuan (1995) é: Os lugares humanos variam grandemente em tamanho. Uma poltrona perto da lareira é um lugar, mas também o é um estado-nação. Pequenos lugares podem ser conhecidos através da experiência direta, incluindo o sentido íntimo de cheirar e tocar. Uma grande região, tal como a do estado-nação, está além da experiência direta da maioria das pessoas, mas pode ser transformada em lugar - uma localização de lealdade apaixonada - através do meio simbólico da arte, da educação e da política (TUAN, 1995, p. 149).

${ }^{3}$ Todas as forças técnicas da economia capitalista devem ser compreendidas como agentes de separação. Debord (2003).

${ }^{4}$ Junto a essa afirmação Massey (2000) enfatiza: "Lugares não possuem uma única identidade, eles estão cheios de conflitos internos. A especificidade de um lugar deriva do fato de que cada lugar é o foco de uma mistura distinta de relações sociais externas e locais. Essa mistura num lugar produz efeitos que não ocorreriam de outra forma. Todas essas relações se interagem com a ajuda da história acumulada do lugar, produto de camadas sobre camadas de diferentes conjuntos de elos e vínculos locais e com o mundo exterior" (MASSEY, 2000, p. 183-184).

${ }^{5}$ A palavra pausterização é entendida de acordo com Debord (2003) como um termo específico que tenta mostrar que as relações sociais fruto da relação com a globalização estão cada vez mais caminhando para uma homogeneização das formas e das funções.

${ }^{6}$ Segundo Souza (2005) a solidariedades definem usos e geram valores de múltiplas naturezas: culturais, antropológicos, econômicos, sociais, financeiros, para citar alguns. Mas as solidariedades pressupõem coexistências, logo pressupõem o espaço geográfico.

${ }^{7}$ Essa perspectiva é vista também por Souza (2005) que enfatiza: Partindo da sua interessante reflexão que neste período histórico (capitalismo globalizado) que Santos (2002) denominou de técnico, científico e informacional, mundo e lugar se constituem num par indissociável, tornando, no entanto, o lugar como a categoria real, concreta. O lugar é também, segundo inspiração sartreana, o espaço da existência e da coexistência. O lugar é o papável, que recebe os impactos do mundo. O lugar é controlado remotamente pelo mundo. No lugar, portanto, reside a única possibilidade de resistência aos processos perversos do mundo, dada a possibilidade real e efetiva da comunicação, logo da troca de informação, logo da construção política.

${ }^{8}$ Santos no seu livro Por uma nova globalização calcando-se na ideia de François Perroux (1961) indicando a descrição de um espaço e econômico e que Castells (2000) retoma essa discussão definindo de espaços defluxos. Então esse sistema de produção é definido pelas redes.

${ }^{9}$ No mesmo livro Santos referindo-se novamente a ideia de François Perroux (1961) descreve esse espaço como banal sendo uma oposição ao espaço econômico. Esse espaço banal seria o espaço de todos, ou seja, o espaço das vivências tendo uma extensão contínua. 
PIMENTEL NETO, J. G.; LIMA, I. V.; SILVEIRA K. C..
O LUGAR E O NÃO-LUGAR A PARTIR DA ANÁLISE DA PERCEPÇÃO: UM ESTUDO

DE CASO DOS CONSUMIDORES NO SHOPPING CENTER DA CIDADE DE

\footnotetext{
${ }^{10}$ Harvey (1995) utiliza este conceito para enfatizar que o espaço a cada dia que se passa estão mais contínuos. Esse efeito é ocasionado pela difusão da tecnologia nos diversos espaços do planeta, assim quem proporciona isso é a tecnologia onde reduz o tempo gasto nas diversas ações diárias.

${ }^{11}$ Outro indicador importante para a ida ao Imperial Shopping é a questão climática do município de Imperatriz, pois é um clima tropical com inverno seco (Aw) de acordo com a classificação de Köppen, tendo uma média de temperatura de, aproximadamente, $25^{\circ} \mathrm{C}$. Esse condicionante ambiental natural indica que o local é muito procurado por parte dos cidadãos da região já que o ambiente é climatizado e com vários tipos de loja gerando muitas opções de atividades e consumo
} 